\title{
Designing for Transition: Supporting Teachers and Students Cope with Emergency Remote Education
}

\author{
Jennifer K. Green ${ }^{1}$ (D) Marla S. Burrow ${ }^{2}$ (D) Lucila Carvalho $^{3}$ (D)
}

Published online: 24 August 2020

(C) Springer Nature Switzerland AG 2020

\begin{abstract}
The global pandemic reached New Zealand in the middle of a teaching semester, calling educators to rapidly transition into a fully online teaching mode. Covid-19 brought fears for the unknown and required an abrupt shift, creating anxiety for academic staff, students and parents. Amidst this transition, educators had to quickly reconfigure their designs, as specific pedagogical strategies set for in-class arrangements would no longer be appropriate for the new scenario. A whiplash redirect to the online mode introduced new tools and added uncertainties about Internet access and connectivity. People had to deal with remoteness and isolation and with changes to virtual learning. This paper theorizes about what it means to design for transition during an emergency. Drawing on the Activity-Centred Analysis and Design (ACAD) framework, we discuss implications for educational design, detailing how tools, social arrangements and tasks can be carefully orchestrated to support learning activity in emergency remote education. We situate the discussion within the transitioning experiences of students and staff at a Bachelor of Nursing programme, within a three-phased educational design which involved Virtual Happy Hours (VHH). The VHH sessions were run with two cohort groups of first- and second-year students in the Bachelor programmeand included their teaching staff. The intent of the VHH was to allow participants to familiarize themselves with tools, tasks and social elements that could be (re)used to facilitate engagement in a new online space - in preparation to the upcoming course sessions in the lockdown period.
\end{abstract}

Keywords Design for learning · Covid-19 · Hybrid learning · Postdigital · Nursing education · Undergraduate

Jennifer K. Green

j.k.green@massey.ac.nz

Marla S. Burrow

m.s.burrow@massey.ac.nz

Lucila Carvalho

1.carvalho@massey.ac.nz

Extended author information available on the last page of the article 


\section{Introduction}

The Covid-19 outbreak emerged in New Zealand in early 2020, its arrival coinciding with the middle of a teaching semester. Like elsewhere across the globe, universities and schools had to rapidly transition to online and digital education formats, adopting remote modes of teaching and learning, whilst impending closures of all schools and universities were being announced. The event brought anxiety for many teaching staff and students, in a mix that included health and economic concerns for the unknown circumstances of the future ahead, and also elevated education to an 'emergency matter' category, with remote learning and educational technologies repositioned as essential services - as a frontline emergency service (Williamson et al. 2020).

The embedding of digital technologies as part of education practices are not new nor unique to the global pandemic - distance education and networked learning have been around for many years. Traditionally, the online mode has been associated with ideas of flexibility of teaching and learning anywhere, anytime (Hodges et al. 2020). But recent discussions in the field have been arguing for a postdigital perspective in education, challenging the usefulness of binary distinctions that place learning activity as face-toface or online, foregrounding that both the digital and non-digital, material and social, are intrinsically interconnected in educational design and in the unfolding teaching and learning activities (Carvalho et al. 2017; Fawns 2019; Jandrić et al. 2018; Ryberg and Sinclair 2016). A broader understanding of learning also suggests that learning does not only happen when students and teachers are together in a classroom (or in an online space) - learning can be connected to work that is outside allocated spaces and set times for education, for example, as students are writing in a library, or exchanging ideas in the cafeteria, or reading on public transport (Gourlay and Oliver 2018). Learning activity might involve searching, finding, selecting topics of interest, reading and writing texts, reflecting on experiences, creating knowledge artefacts, communicating ideas and participating in synchronous or asynchronous sessions with teachers and peers. In many of these activities, a mix of digital and material tools, ideas and people may be at play.

Still, there was a clear perception in early 2020 that a 'move to the online' sphere was taking place, even if such a move was not necessarily new. The difference in the Covid-19 scenario was the speed and urgency with which 'the move' was expected to happen and how 'the move' itself was surrounded by anxiety about an unknown situation that involved a global pandemic. Different countries had more or less numbers of cases and deaths, but this sense of 'emergency' was a shared worldwide experience, arguably acutely felt by educators, students and parents - from kindergarten through to higher education.

Essentially, for educators, this transitioning moment required quickly redesigning what they had prepared in advance for the teaching semester; plans for what once would shape face-to-face classroom activity of teachers and students at certain allocated spaces and times now required transition to incorporate tools, tasks and social arrangements in an online environment. At non-pandemic times, similar redesign has long been considered a complex endeavour. Teaching requires investment in specific pedagogical strategies, and in any type of setting (whether it involves synchronous or asynchronous interactions, 'online' or 'off-line'), it includes backstage orchestration of tools, tasks and social organization to foster productive learning activity. What happens 
at learntime - or the moment when teachers and students interact - has usually been carefully planned in advance, through choices made by educators about types of tools and resources that will be available to students, the pacing and sequencing of knowledge and decisions about specific social arrangements, such as group work and individual tasks. A whiplash redirect to an online mode introduced different elements, such as having added uncertainties about Internet access or connectivity, learning about new types of technology and how to handle/manage an online synchronous/ asynchronous space, feelings of isolation and remoteness and preoccupation about performativity in virtual environments, all amidst personal circumstances and concerns about health and economic affairs. As such, the sudden shift to a fully online mode was marked by the need for educators to quickly figure out how to redesign their own courses - to think about ways of adapting what had been prepared for the semester ahead to fit a new mode and with new tools. Educators also needed to account for the affective dimension associated with the shift. In this paper, we theorize about what it means to design for transition as part of an emergency response to remote education during the Covid-19 outbreak. Drawing on a networked learning perspective - the Activity-Centred Analysis and Design (ACAD) framework (Goodyear and Carvalho 2014) — we discuss the reconfiguring of university courses through a case study, experienced at a New Zealand University. We detail how tools, social arrangements and tasks carefully scaffolded students and teachers into experiencing a new learning environment - and the underlying design intentions at each step of the way. The paper shows that as teaching staff and students were getting ready to go 'live' with online teaching and learning in the Bachelor of Nursing programme, a series of Virtual Happy Hours (VHH) using a video conferencing platform was created. Cohort groups for each year in the Bachelor of Nursing had opportunities to participate in the VHH sessions, which were carefully designed to pace their transitioning experience into a new mode. By deliberately not including disciplinary knowledge, these sessions were run as fun events albeit, as we will show, these were essentially also learning events, which allowed two aspects of the transitioning process to be addressed. First, they created opportunities for bringing people together to experience a fun activity in times of deep distress. Second, they offered moments to learn about how to navigate a new learning environment, at low stakes learning sessions. In so doing, they helped students and teachers to manage anxiety related to learning something new on the run. Challenges associated with the redesign also emerged, such as how to sensitively identify and address the emotional elements associated with the Covid-19 scenario and how to identify and support those experiencing digital inequalities (Czerniewicz 2018).

\section{Designing for Transition in a Postdigital Era}

Design for learning not only involves coming up with learning tasks or suggestions of things for students to do but also includes intricate considerations about how social and physical elements may come together to influence the emergent learning activity (Goodyear and Carvalho 2014). Whilst design often provides a structure that will influence learning activity, Goodyear and Dimitriadis (2013) remind us to be wary of assumptions about learners' compliance - as learners have autonomy to interact, rearrange and co-configure whatever is proposed. At times, considerations about the digital seem to make design issues more salient, 
perhaps because there is an element of novelty in those contexts (Beetham and Sharpe 2019; Fawns 2019). But the digital (along with the material) should be seen as a part of the physical. It is perhaps easier to notice this interconnectedness in the physical environment of a 'face-to-face' classroom, when we consider that a face-to-face scenario might often involve students using a laptop and the Internet to do some research on a given topic; a teacher may decide to present a YouTube clip for discussion; or students and teachers may communicate via a Learning Management System on a given task whilst still co-present in the physical space. Indeed, these types of scenarios raise questions about the boundaries of a 'learning environment' that distinguishes 'face-to-face classroom activity' from 'online activity'.

Similarly, recent debates in education have been critical of the use of terms such as 'online learning' or notions that imply that learning is happening in an online or digital world, detached from the physical realm, as if one is disembodied (Fawns et al. 2019). Bayne and Jandrić (in Jandrić 2017) suggest that our interactions with the digital should not be understood as a disembodied experience, but, instead, as involving co-presence in multiple spaces which we all inhabit in our everyday lives. In other words, the digital and physical spaces are inextricably linked. It is possible to be in a cafe and yet be talking to a friend overseas. People may be attending an online seminar, but their physical bodies are still grounded on the surroundings of their bedrooms or lounges at home. Whilst some may use terms such as blended-learning, online-based or classroom-based teaching to try to differentiate between design scenarios, these characterizations are not necessarily useful when seen in isolation. Every design scenario will require consideration about an intricate web of elements - including the learning tasks, the digital and materials at hand, different ways people may be organized and specific arrangements of furniture in the space.

The pandemic reached us all in this postdigital era, and so within the Covid-19 scenario, many conversations emerged about how the boundaries between work and home, university and home, were now being perceived as morphed into one single experience. The impact of people's situation at home seemed to make this notion of postdigital much more evident, as people's situations were more salient, for example, for those who were now home-schooling their children whilst having to work/study from home, those who had to take turns and share one computer amongst diverse family members and those trapped into an unsafe household.

Overall, a postdigital perspective calls for education to be seen as not an entirely physical nor entirely online endeavour. Instead, learning activity is understood as often involving a complex combination of elements - which include digital and material tools and resources, ideas, tasks and people, all enmeshed in a network of elements (Carvalho et al. 2017; Fawns 2019; Jandrić et al. 2018; Ryberg and Sinclair 2016). Our research takes a networked learning perspective, which in its essence reflects relationships between technologies and the processes of learning and education (Jones 2015). Networked learning has been around since the early 1990 s, when it emerged as primarily connected to the use of technology for learning within the tertiary sector. Technology has since significantly evolved, transforming and extending learning experiences through ubiquitous and portable technologies, and accordingly, networked learning has also evolved and shifted from its initial focus in higher education to embrace broader educational practices, such as those connected to informal learning, work-based and professional development (Hodgson et al. 2014). 
Networked learning combines ideas from critical theory and implies an active social role with individual agency of learners and educators (Hodgson et al. 2012; Jandrić and Boras 2015; Jones 2015). In taking a networked learning stance, one focuses on openness and fluidity, on support and building shared understandings of a particular phenomenon and on promoting cooperation and collaboration in the learning process (Hodgson and McConnell 2019). A high value is placed on group and community work and on learning through discussion and dialogue. As Hodgson and McConnell (2019) highlight, there is value in the 'difference', and this 'valuing of difference' plays a key role in the learning process. Importantly, networked learning embodies a sociomaterial dimension, as it involves the use of technology to connect and mediate learning activity (Goodyear et al. 2004; Hodgson and McConnell 2019).

Within the Covid-19 context, and in considering how to design for transition in a university Bachelor programme, we were acutely aware about the importance of using technology to promote connections, collaboration and participation. We were also aware that a range of elements would be likely to be at play in terms of digital tools, tasks and social structures. But two elements were also brought to the fore in the scenario of emergency remote education. First, it raised considerations about people's affective mood, and the need to acknowledge and support those experiencing physical and mental distress. In our design, we needed to consider these issues as part of our social structure. Second, there were issues associated with digital access and connectivity, and a potential gap often referred to as digital inequality (Czerniewicz 2018) became more salient. As Czerniewicz (2018) explains, inequality of resources is only one of the inequality dimensions. Whilst economic issues such as costs of data and availability of connectivity may be at play, there are also other issues associated with cultural capital (e.g. digital literacies) and issues that ultimately may greatly impact one's life and self-development, autonomy, freedom, etc. This was particularly relevant in a scenario where education was suddenly elevated to an 'emergency matter' category or as remote learning and educational technologies were being repositioned as essential services (Williamson et al. 2020). In what follows, we introduce the analytical ideas that we used to frame the structural elements in the design for transition and to theorize how these elements were likely to influence learning activity at hybrid learning spaces. We then illustrate and discuss broader principles for how one may design for transition in a remote education emergency.

\section{Framing Learning Activity-Set, Social and Epistemic Design}

Carvalho and Goodyear (2019) refer to learning networks as a phenomenon for inquiry where the main focus is on understanding what participants in a network are coming to know, for what purposes do they come together, what strategies they use and what tools and resources are available to them. In order to understand the functioning of a productive learning network, researchers need to identify and investigate various elements involved in a network, examining their relations and boundaries. This understanding can then be used to improve existing designs and/or to (re)design for the needs of other learning networks. The analytical lenses of the ACAD framework (Goodyear and Carvalho 2014) helped us identify and abstract a structural composition within the constraints of a case study within the Bachelor of Nursing at a New Zealand University 
and to then formulate principles to be considered when designing for transition for remote emergency education more broadly.

The ACAD framework is now a well-established metatheoretical framework, which has helped many educational designers and researchers to foreground connections between designable elements and emergent learning activity in a range of learning situations (Goodyear and Carvalho 2014; Carvalho and Yeoman 2018, 2019; Munoz et al. 2018). The designable elements acknowledge the physical, social and epistemic nature of learning and are conceptualized through three dimensions of design — set design, epistemic design and social design. Set design refers to digital and material elements in a learning situation. It acknowledges that as part of the design process, educators make choices about digital tools and platforms and/or material elements that will be available to learners, such as pen and paper, smartphones and apps or arrangements of furniture in a classroom. As part of this dimension, one would include considerations about resources, such as availability of laptops and data costs which may impact learners in an emergency situation. Epistemic design refers to the learning task - as educators make choices about things for learners to do and consider ways of structuring (sequencing and pacing) knowledge and information. The nature of social arrangements is enacted through social design and may refer, for example, to the formation of groups, having scripted roles or scaffolds for the division of labour. In many educational settings, attention is often paid to the epistemic and social design, whereas the role of the digital and material elements tends to still receive less emphasis. ACAD reminds us that these three dimensions are important when designing for learning, and they all influence learning activity. A fourth dimension of the ACAD framework acknowledges learners' agency to re-configure and co-construct what has been designed in advance by educators. This dimension foregrounds learning activity as emergent and is referred to as the co-creation activity (see Fig. 1).

At learntime, choices for elements in set, epistemic and social design become an assemblage of elements, and as learners interact with this assemblage, they may reshape and co-configure what has been proposed as they exercise their agency to cocreate. In what follows, we draw on the ACAD framework detailing the rationale adopted to design for transition in emergency remote education. The rationale builds on the experience of supporting teachers and students in the Bachelor of Nursing as they transitioned from an emphasis on face-to-face interactions to one that would include the use of video conferencing during the pandemic outbreak.

\section{Virtual Happy Hours-Scaffolding the Use of Tools and Social Arrangements}

\section{Participants}

This study involved two cohort groups of first- and second-year students enrolled in the Bachelor of Nursing, which comprised approximately 300 students in total and 27 academics and tutors. Two VHH sessions were organized with the year one and two cohort groups. Two academic staff from the Bachelor of Nursing with expertise in online teaching and learning acted as VHH facilitators of these sessions. All students and teaching staff were invited to participate in the VHH sessions-automatically 

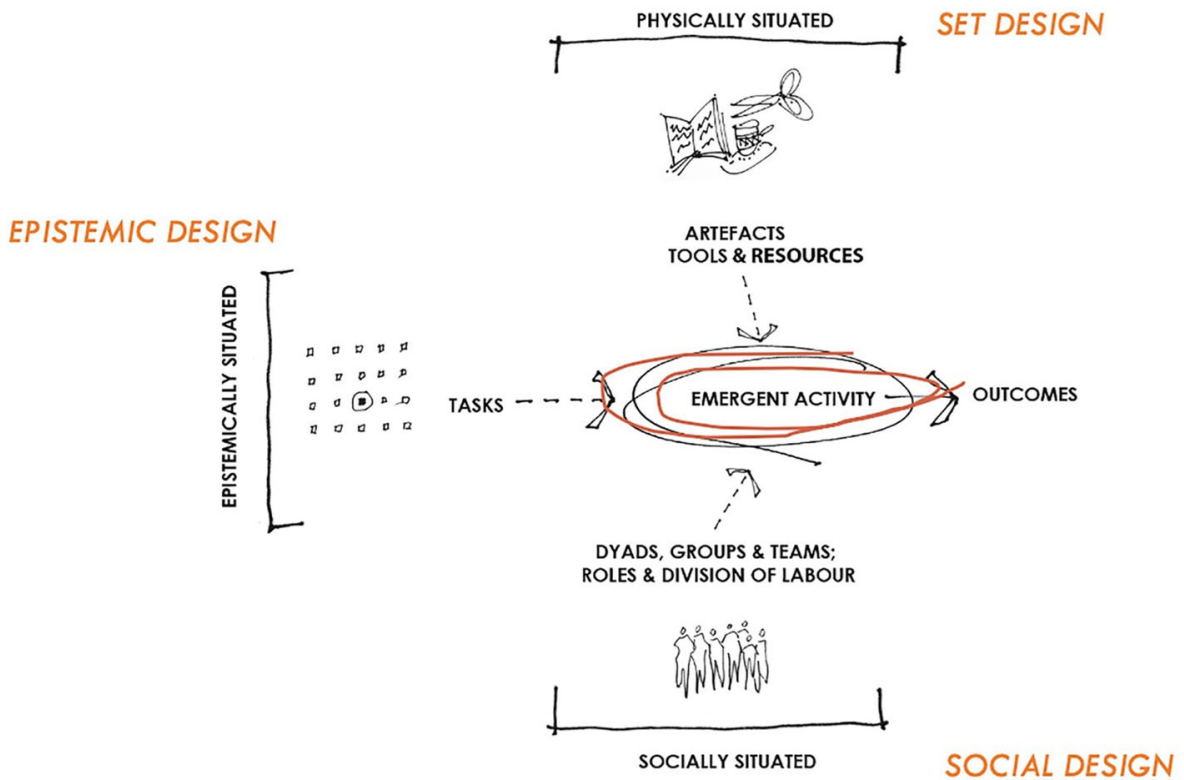

Fig. 1 ACAD framework (adapted from Goodyear and Carvalho 2014, p.59)

generated meeting reports showed that there were 90 students and 10 staff that attended either one or both VHH 1 and VHH 2. Participants included students enrolled in courses taught by the $\mathrm{VHH}$ facilitators and teaching staff who were directly involved with a cohort and/or who attended for the benefit of their own professional development. The VHH sessions were held on the week prior to resuming teaching, after a 4week Covid-19 lockdown teaching pause. Students were in mixed situations, for example, some were enrolled in semester one courses that were yet to finish, and all were scheduled for courses that would be transitioned to online in the following semester. There was emergent need for staff and students to get familiar with new teaching and learning arrangements; however, participation was also dependent on their availability, under the extraordinary circumstances of the lockdown period, which were very different than what people usually experience during traditional academic breaks between semesters.

\section{Design Structure}

With Covid-19, the need to redesign courses happened as part of a public health emergency moment, which also had political, economic and social characters associated with its emergency nature (Williamson et al. 2020). Stress, uncertainty and anxiety were implicitly or explicitly present at first, bringing the affective nature in learning to the fore. Students and staff would have a variety of arrangements in their physical home settings, which could include having to deal with technical concerns (e.g. access to Internet and connectivity or having to negotiate access to a device with other family members), spatial arrangements (e.g. having a dedicated space for study sessions), family (e.g. having carer responsibilities) and physical and mental health stress (e.g. being part of the vulnerable at risk group or having anxiety about job related issues). 
Considerations about these multiple dimensions connect well with existing practices within the Bachelor of Nursing programme, which incorporates a holistic view of learning. The Bachelor programme incorporates Te Whare Tapa Whā (Durie 1985), an Aotearoa New Zealand devised framework for health and wellness, which is foundational in planning and providing healthcare (see Fig. 2). Aspects of health and wellness are represented holistically as the Tapa Whā (four walls) of a Whare (house) and include Taha Whānau (family and relational), Taha Tinana (physical), Taha Hinengaro (emotional) and Taha Wairua (spiritual) wellbeing. Te Whare Tapa Whā foregrounds that the interrelationship between each of these dimensions supports holistic care.

Many of the tasks proposed in the nursing courses invite students to think about health holistically, for example, as students are asked to identify their own personal health and wellness in terms of Te Whare Tapa Whā. Thinking about their own wellbeing is important, so that they can empathize and consider the wellbeing of others. Students might consider their wellbeing holistically, for example, using a website Meke Meter $^{1}$. The Meke Meter is a wellbeing self-assessment tool which considers social, physical and mental aspects (Forrest et al. 2019). Our design for transition took these ideas into account-where the wellbeing of staff and students should be noted, particularly in this moment of stress and uncertainty.

Design decisions took multiple factors into account, such as considerations about the affective mood, but it was also important to find out the types of technical and spatial difficulties students and teachers might be having. Identifying and addressing these difficulties were a crucial part of the process, as our goal was to support their successful transition into the new learning environment, breaking down the complexity of some of the elements (tools, tasks and social arrangements). Concerns about the networked learning values were also present (Hodgson and McConnell 2019), and these involved figuring out ways of enabling and/or scaffolding participation and collaboration within the new learning environment.

Scholars in the learning sciences have explored the role of scaffolding in a range of complex learning situations (Davis and Miyake 2004). Kolodner et al. (2003) argue that special kinds of scaffolds can effectively prepare participants for collaborative practices in a community. The authors suggest a phased design for collaborative learning situations, where initially students are asked to collaborate to solve simple problems. Kolodner et al. (2003) argue that these problems should be representative of those they will encounter in the future, for example, by including some of the reasoning skills students will need later, when they interact with more complex content. By engaging in these activities (alongside discussions about students' reasoning), students are supported to understand the value of collaboration and are more likely to productively collaborate in future interactions.

In designing for transition, it was important to use a phased design structure, not only to scaffold collaborative activity (social design) but also to gradually expose students and staff to different set design elements. The initial VHH sessions purposefully focused on experiencing and learning how to navigate within the online platform,

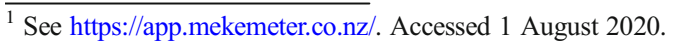




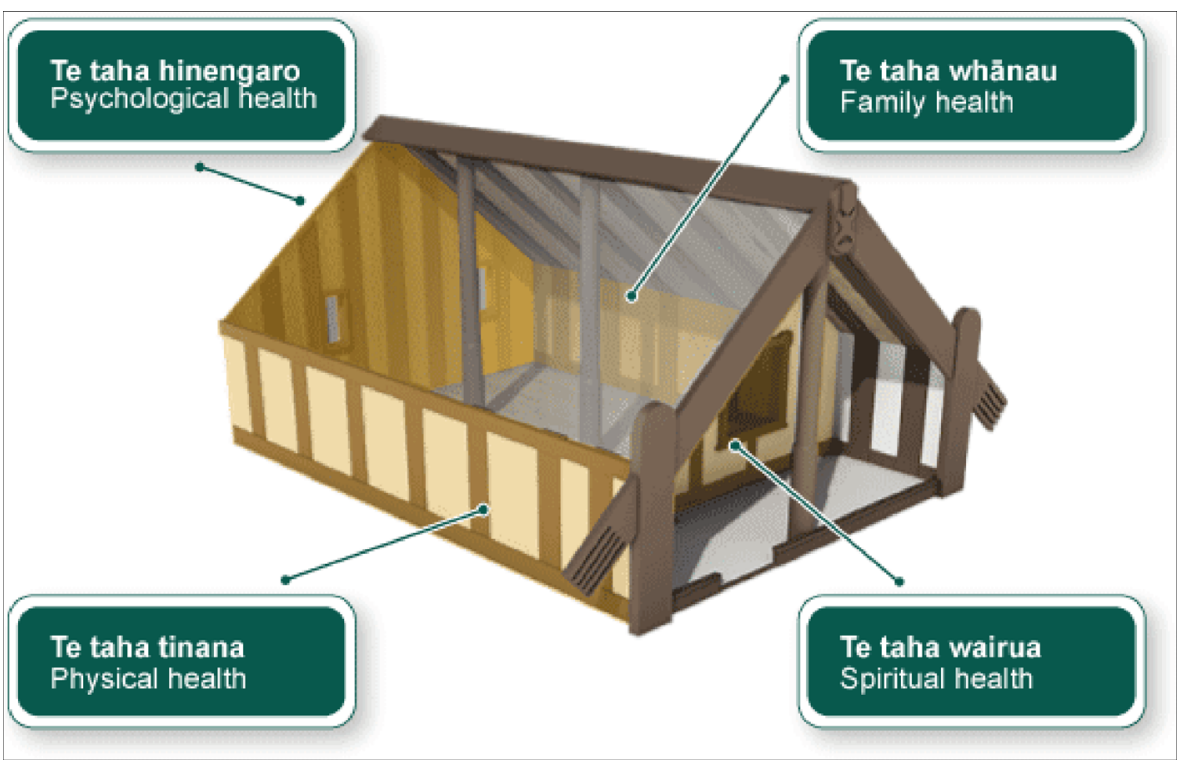

Fig. 2 Te Whare Tapa Whā (NZ Ministry of Health 2012)

without overwhelming participants. As such, phase 1 was necessary, for the successful implementation of the subsequent phases.

Table 1 illustrates the overarching three-movement framing in the setup of the design for transition.

Table 1 Design for transition - three movement framing

\begin{tabular}{|c|c|c|c|}
\hline $\begin{array}{l}\text { ACAD } \\
\text { Framework }\end{array}$ & Phase $1-\mathrm{VHH}$ prior to course & $\begin{array}{l}\text { Phase } 2 \text {-live course in } \\
\text { lockdown (part A) }\end{array}$ & $\begin{array}{l}\text { Phase 3-live course in } \\
\text { lockdown (part B) }\end{array}$ \\
\hline Set design & $\begin{array}{l}\text { - Introduction of video } \\
\text { conference platform } \\
\text { - Introduction of specific features } \\
\text { such as poll, whiteboard, chat, } \\
\text { annotation tools } \\
\text { - Overview of activities PDF }\end{array}$ & $\begin{array}{l}\text { - Video conferencing platform } \\
\text { - Polls, text chat, annotation tools } \\
\text { - Overview of activities PDF }\end{array}$ & $\begin{array}{l}\text { - Video conferencing } \\
\text { platform } \\
\text { - Poll, whiteboard, } \\
\text { chat, annotation } \\
\text { tools } \\
\text { - Written course notes }\end{array}$ \\
\hline Social design & $\begin{array}{l}\text { - All participants experience } \\
\text { online plenary room }\end{array}$ & $\begin{array}{l}\text { - Introduction of variation in } \\
\text { social design } \\
\text { - Online plenary \& breakouts } \\
\text { rooms }\end{array}$ & $\begin{array}{c}\text { - Online plenary \& } \\
\text { breakout rooms }\end{array}$ \\
\hline $\begin{array}{c}\text { Epistemic } \\
\text { design }\end{array}$ & $\begin{array}{l}\text { - Low stakes task-happy } \\
\text { hour games } \\
\text { - Investigation of difficulties } \\
\text { (access, technical, personal } \\
\text { through anonymous poll) }\end{array}$ & $\begin{array}{l}\text { - Low stakes task-review of } \\
\text { pre-learning formative quiz } \\
\text { in groups and whole class } \\
\text { - Live gathering of shareable } \\
\text { data for discussion at } \\
\text { interactive activities }\end{array}$ & $\begin{array}{l}\text { - Nursing course } \\
\text { content } \\
\text { - Case study } \\
\text { - Conceptual } \\
\text { frameworks for } \\
\text { long-term health } \\
\text { conditions }\end{array}$ \\
\hline
\end{tabular}




\section{Phase 1-Fun Activities Prior to Online Course}

A 1-hour VHH session was set up using a video conferencing platform (set design), for each of the year groups in the School of Nursing courses. The transition to the online environment used the established class cohorts to capture as many students and staff as possible (social design). Invitations to the virtual, bring your own beverage, 'happy hour' were sent through online posts and email via the courses' websites. Our intention in naming the sessions as VHH was to allude to a moment where people could get together for a convivial, social encounter. Lecturers who joined in were able to survey the scene without any obligation to direct or manage the learning activity themselves. This allowed lecturers, as well as students, to experience the dynamics of the online classrooms in a no-risk and fun session (epistemic design). This 'low stakes' involvement of lecturers raised their interest and led to other requests; for example, the facilitators were asked to run other $\mathrm{VHH}$ sessions for postgraduate cohorts and to facilitate the initial online meeting sessions of various post-graduate and undergraduate courses.

At the start of each of these VHH informal events, polls (set design) were used to find out how participants were feeling and to ask about the reliability of their Internet connection. This offered an opportunity to bring everyone together as a group and to create a convivial online space (social design) whilst acknowledging the affective nature of the public health emergency we were all experiencing. The polls also provided valuable information about the availability of tools and technologies and any technical difficulties (set design). This was a crucial move to identify those who needed support in troubleshooting or those who had difficulties with potential access to the Internet and device availability. This information was then considered in preparation for, and expectations of, the rollout of the Bachelor of Nursing online courses in the subsequent week (phase 3).

New Zealand's self-isolation lockdown occurred over the Easter holidays, a time when many people usually travel to visit family or holiday. The VHH 'party games' were created to encourage participation and interaction with different features in the video conferencing platform (set design). One of these involved the use of a 'whiteboard' and the host/facilitator sharing their screen and annotation tools to engage participants with the task of creating the ideal beach holiday scene. During the activity, the participants drew items deemed essential for a beach holiday, for example, sunshine, music, ice cream, boats and fishing, and the ubiquitous roll of toilet paper (see Fig. 3). Students were then invited to talk about their 'essential' holiday items, in an activity aimed at creating a convivial environment (social design) where participants could share humour at a time when anxiety was prevalent and, as such, addressing the affective nature of learning. The activity created rapport between facilitators and participants, and opportunities to showcase and experience using annotation tools (set design), and what is possible to do with those elements in the online classroom.

Other elements were further scaffolded with the introduction of a PollEverywhere quiz (set design) in which participants were asked to link famous movie lines to movie titles. The quiz activity enabled consensus creation through 'upvoting' on what was considered a 'low stakes' task (epistemic design). In that way, participants experienced interacting with elements of the platform (set design) but without having to worry about disciplinary knowledge. 


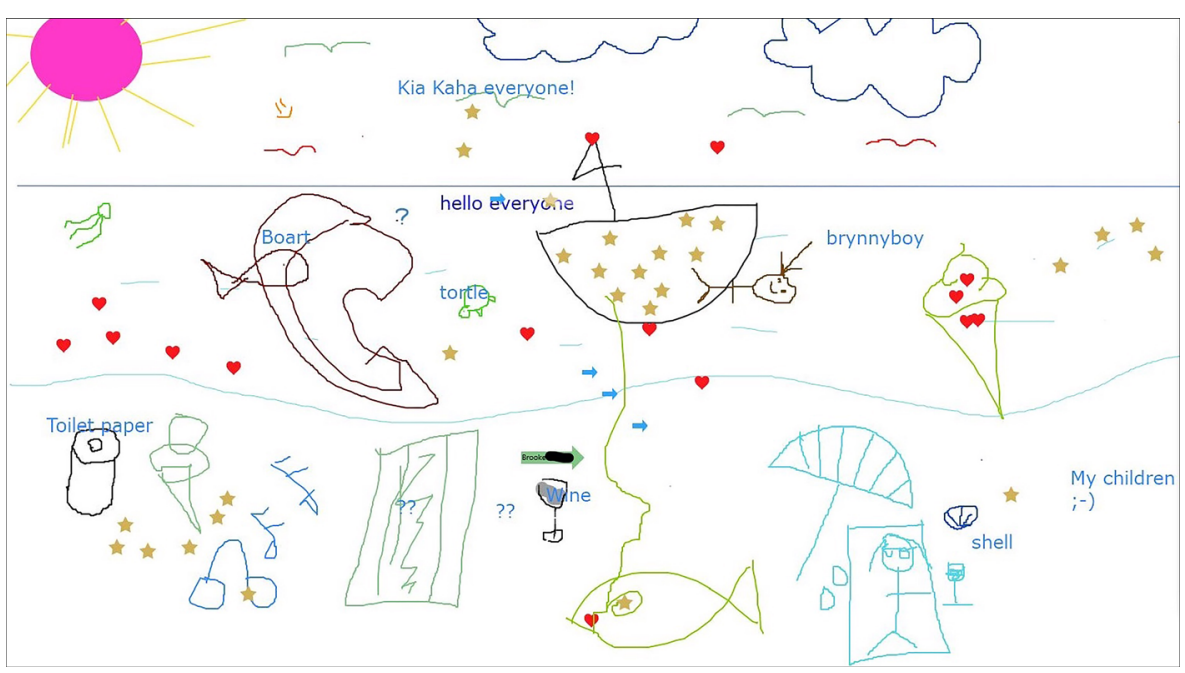

Fig. 3 Virtual happy hour — beach holiday essentials on shared whiteboard

Designing for transition during emergency remote education involved figuring out how to best support staff and students transition to the online format in a situation where there was minimal time for formal training, as many staff were focused solely on transferring their face-to-face course content to the online space. The VHH was therefore a crucial phase in designing for transition. At the end of the $\mathrm{VHH}$, students seemed highly engaged, and the proposed tasks created learning moments for them to experience the use of the platform and to interact with each other. Staff observed different ways of facilitating an online session whilst experiencing themselves the use of different features of the platform. Importantly, both staff and students had an enjoyable social time.

\section{Phase 2-Introducing Variations in Social Design: Live Course in Lockdown}

The second event happened 4 days after the VHH session was held. The intent in this first live learning session (part A) was to break down complexity by creating opportunities for participants to experience variations in social design. Part A introduced work in small online groups (social design) through breakout rooms (set design). Breakout rooms are a feature of the video conferencing platform, which splits the large group into smaller groups, and a facilitator can either automatically or manually allocate people into groups. A shift into breakout rooms has the potential to be a harrowing participant experience if not managed well. It is essential to provide clear direction, both written and spoken, prior to moving participants into breakout rooms, so that activities and expectations are understood by all and therefore able to be achieved. Once in the breakout rooms, each with 3-4 participants, a low stakes task was proposed (epistemic design), which involved participants introducing themselves and discovering whose birthday was closest to that day's date, with that person becoming the leader for subsequent group activity. These tasks were based on teaching engagement strategies that students would experience in their course activities in the upcoming months (e.g. working in groups, assuming different roles within a group and participating in quizzes) and involved students using elements of the platform (set design) 
that would be used in the phase 3 teaching, when the courses in the Bachelor of Nursing programme were live.

A core concern in this design for transition was to support lecturers and students to cope with their experiences of emergency remote education. The phased design gradually introduced new elements, which were carefully sequenced and paced (epistemic design) to not overwhelm participants in a moment of stress. The phased design also provided opportunities for staff to troubleshoot technology issues either in session or post-session. Jowsey et al. (2020) highlight that students expect teaching staff to be able to resolve technology issues in a timely way. These issues ranged from guiding students in how to find the invitation to their breakout room, facilitators joining breakout rooms to assist with finding and using annotation tools, to identifying whether students' Internet bandwidth required them to reconnect to the meeting platform and then be re-allocated into their breakout room. These sessions also helped to identify students who required assistance with hardware or software downloads and enabled us to connect them with university support staff. These initial low stakes sessions empowered staff and students to work together and to create solutions which were presented in text, audio and video in subsequent sessions. In addition, solutions to frequently raised issues were used to refine the planning for the online sessions in phase 3 and contributed to a 'run-sheet' template that was distributed to all teaching staff.

Although the design of tasks (epistemic design) in phase 2 was considered low stakes, as they involved formative assessment of nursing knowledge, careful instructions to support participants' engagement were essential (Jowsey et al. 2020). This experience informed the design of a PDF used in phase 3, when prior to the live meeting, an overview of what was planned for the session was shared with students and teachers - including screen capture of various elements of the video conferencing platform. The aim was to assist those who were unfamiliar with the features of the platform to find their way, particularly those who might have been using limited screen space or participating via smartphones or tablets (set design).

In phase 2, however, a presentation software was used to share the overview of activities, and participant's engagement was invited via the use of text-based chat and verbal instructions during this session, to guide participants in finding and using the shared screen and annotation tools in the video conferencing platform (set design). We realized that an overview PDF (set design) would provide extra support for students in terms of the organization of tasks (epistemic design), types of social engagement (social design), timings to navigate the tasks and clarity on facilitation roles during the session.

In creating the $\mathrm{VHH}$ and phase 2 design for transition, we were acutely aware that learning tasks should provide opportunities for students to experience a sense of belonging, to feel connected to others (social design), to engage within the online environment. Meyer and Allen (1991) refer to the three-component commitment theory, suggesting that people engage and perform better when cognitive, normative and affective aspects are all present in an enterprise. And so, the aim was to emphasize each of these within the online learning environment and in doing so to create a robust learning experience. We argue that the phased approach supported students in experiencing the use of different features on the online meeting platform (set design), as cognitive and normative aspects were introduced seamlessly (Meyer et al. 2002). Such scaffolding supported participants' experience of technology-enhanced learning (Green and Huntington 2017) and provided an important foundational experience for phase 3 . Phase 1 
and 2 enabled students and teaching staff to become familiar with the environment in which they would be teaching and learning for the remainder of the semester.

\section{Phase 3-Building on Experiential Foundation: Live Course in Lockdown}

The implementation of $\mathrm{VHH}$ enabled teaching staff to consider possibilities for their own online learning sessions. As such, it was also a learning experience for academics who were unfamiliar with online teaching and learning. Jowsey et al. (2020) argue that staff needs to learn how to teach in online environments in order to support quality, technology-enhanced teaching and learning experiences for their students. The experiences of staff and students in the $\mathrm{VHH}$ and phase 2 sessions led to the provision of staff-only tutorials, where the breadth of the functionality of the video conferencing platform could be further demonstrated and explored.

It also led to the development and refinement of design artefacts to help teachers and facilitators, such as the creation of an online session run-sheet template. This document aimed at facilitating the planning and revision of a lesson's content-in terms of the elements that can support students' transition of face-to-face classroom activity to the virtual learning meeting space. As a design artefact, the run-sheet template also evolved, to accommodate what the facilitators learned in phase 1 and 2. The runsheet was modified to include visual icons that enhanced instructional text - for example, an image of a timer to prompt the online facilitating teacher to start a timer for breakout room sessions. These elements offer visual cues, helping facilitators and learners to quickly identify what is next at learntime.

Relationships between academic staff also evolved. Team teaching and peer review for facilitation roles became more salient after the three phases, leading to collaborative teaching and students' engagement and rich participation in online environments. Throughout this process, the Nursing staff and students have become increasingly familiar and comfortable with the tools (epistemic design) and the types of social arrangements (social design), thereby reducing apprehension and uncertainty going forward. This meant that when the nursing online course began, there was less concern about the features of the platform (set design) and a more natural focus on the online tasks and disciplinary content (epistemic design). Innovative ideas proliferated with academic staff trying out different online pedagogical strategies and sharing their learning with others. Feedback from the students mentions that learning experiences have been 'fun' and socially engaging.

\section{Abstracting Overarching Principles for Designing for Transition}

Moving to online teaching and learning, particularly within the context of emergency, can be a scary and lonely experience to both students and teaching staff, a moment that is surrounded by anxiety (Hodges et al. 2020). From the perspective of academic staff, learning how to teach and manage the online space is perhaps best achieved through a team teaching approach where a more experienced facilitator supports the less experienced peer, until they feel confident and competent. From a students' perspective, supporting learners' activity in this new environment through careful scaffolding is essential-for example, as students learn how to manipulate new tools and 
accommodate new social configurations, which, in turn, are influential for productive learning in any given disciplinary field.

Designing for transition evolved within a continuum, in a three-phased approach. The overarching design considered ideas from Dalsgaard and Godsk (2007), who took existing lecture materials and identified essential content within the lecture concepts, adapting it to provide on-demand learning content that supported repetition and flexibility whilst catering for individual student preferences. When Dalsgaard's team first tried to combine all of the content into a single, online lecture experience, students became frustrated at the increased speed and experienced this as a difficult learning situation (Dalsgaard and Godsk 2007). Their strategy was to identify first the 'problems' or questions within the existing material that could be developed into engagement activities, as opposed to the traditional lecture room open discussions, or depending on a response from a single student. The design for transition drew on these ideas to specifically offer support for teaching staff. There was an emphasis on demonstrating how existing lecture materials from traditional lecture halls could be translated and adapted, in content that would encourage more participatory engagement whilst capitalizing on networked learning - or on the use of technology to promote connections, participation and shared understandings (Goodyear et al. 2004; Hodgson and McConnell 2019). We achieved this through offering hands on experiences to staff where they could see how students were guided within the online meeting space, in breakout room discussions, and paired with PollEverywhere polls, as an active means to support whole class participation in problem-solving scenarios. Prior to these events, there was no formal community of practice in relation to teaching at the School of Nursing, but the process of sharing experiences during the transition facilitated staff to come together as a community to discuss new pedagogical practices and saw staff within the School of Nursing moving towards becoming a community of practice (Wenger 1998).

When well designed and carefully scaffolded, online teaching and learning has the capacity to provide socially rich learning experiences. Learning experiences that emphasize online participation will always be different from what one experiences at face-to-face learning sessions at the university learning spaces, but the quality of these interactions is not necessarily inferior. In order to foster an online learning community, it is necessary to carefully consider elements as part of a design assemblage (tools, tasks, social arrangements) that might allow for student dialogue, and create a convivial atmosphere likely to enhance the quality of teacher-student interactions, which are all key aspects of well-functioning learning networks (Goodyear et al. 2004; Kenzig 2015; Swan et al. 2009).

Another important consideration in our design for transition was linked to the affective dimension, on how to support teachers and students to cope with emergency remote education. As such, the VHH sessions incorporated elements to address the health and wellbeing of our students and teachers in this rapid shift to the online mode, for example, creating opportunities where participants could share their experiences with one another, where they could discuss difficulties openly and have a space to support each other.

In what follows, we summarize core general principles for those designing for transition in the context of remote emergency education:

(1) Plan for a phased design that gradually introduces elements of set, social and epistemic design. 
(2) Keep it simple to avoid overwhelming learners, include only a few elements at a time.

(3) Start with a 'low stakes' learning task, with an element of fun-it helps with the affective mood as well as with focus on learning about new elements rather than disciplinary knowledge content.

(4) Work on conviviality and inclusion with tasks that allow multiple voices to be heard.

(5) Bring the affective to the fore, offering safe opportunities to discuss issues (including anonymously) and use these as the basis for jointly exploring potential solutions.

(6) Offer printable resources for those with low connectivity or using small devices.

(7) Use visual cues, for learners and educators, to signal movement between learning spaces, e.g. the use of icons in a PDF to indicate a task and where it will take place - breakouts, plenary, and polling site.

(8) Privilege tasks and resources that require low bandwidth.

(9) Whenever possible, embrace team teaching - it allows for novice-apprentice exchanges.

(10) Organize staff discussions about their experiences - it allows for learning new pedagogical strategies and ways to tackle problems, and builds a sense of a community.

\section{Conclusion}

The global pandemic affected the structuring of teaching and learning practices in the Bachelor of Nursing, not only with the sudden requirement that students engage with lecturers remotely via the use of technology. In some cases, this moment highlighted digital inequality in access, connectivity, and literacy amidst anxiety for the unknown. But the moment also offered an opportunity for academic staff to discuss and learn different ways of teaching, ways of promoting student engagement and collaborative work through team teaching — which were all facilitated by the exchanging of teaching experiences and ideas amongst Nursing academic staff.

Currently, the Nursing School is encouraging teaching staff to capture and share their design ideas. This seemingly onerous task involves taking existing lecture resources and working out how to translate them into interactive online strategies, based on pedagogical principles that encourage active and collaborative learning. In mapping this process, we are bringing together teams of teachers to jointly develop pedagogical strategies that are socially engaging, pleasurable and productive. Whilst a sudden move to a digital teaching experience can be mentally taxing, there is much to be gained from working with others in a team teaching collaborative environment, for both students and teachers. This has been a moment to ponder and to act, to come together as a learning community and to consider what can be our contribution to those around us and, further afield, to others going forward into the future and to those who may experience a sudden transition and the need to quickly reconfigure courses, as we have been experiencing with Covid-19. As Jandrić (2020: 237) reminds us, 'knowledge and solidarity are the key to long-term survival and flourishing of the human race'.

Code Availability Not applicable. 
Authors' Contributions All authors contributed equally to the development of this manuscript. All authors read and approved the final manuscript.Data AvailabilityNot applicable.

\section{Compliance with Ethical Standards}

Conflict of interest The authors declare that they have no conflict of interest.

\section{References}

Beetham, H., \& Sharpe, R. (2019). Rethinking pedagogy for a digital age. New York: Routledge.

Carvalho, L., \& Goodyear, P. (2019). Productive learning networks. In M. Peters (Ed.), Encyclopaedia of teacher education. Singapore: Springer. https://doi.org/10.1007/978-981-13-1179-6_106-1.

Carvalho, L., Goodyear, P., \& de Laat, M. (2017). Place-based spaces for networked learning. New York: Routledge. https://doi.org/10.4324/9781315724485.

Carvalho, L., \& Yeoman, P. (2018). Framing learning entanglement in innovative learning spaces: Connecting theory, design and practice. British Educational Research Journal, 44(6), 1120-1137. https://doi. org/10.1002/berj.3483.

Carvalho, L., \& Yeoman, P. (2019). Connecting the dots: Theorizing and mapping learning entanglement through archaeology and design. British Journal of Educational Technology., 50(3), 1104-1117. https://doi.org/10.1111/bjet.12761.

Czerniewicz, L. (2018). Inequality as higher education goes online. In N. B. Dohn, S. Cranmer, J. Sime, M. De Laat, \& T. Ryberg (Eds.), Networked Learning Research in Networked Learning. Cham: Springer. https://doi.org/10.1007/978-3-319-74857-3_6.

Dalsgaard, C., \& Godsk, M. (2007). Transforming traditional lectures into problem-based blended learning: Challenges and experiences. Open Learning: The Journal of Open, Distance and e-Learning, 22(1), 2942. https://doi.org/10.1080/02680510601100143.

Davis, E., \& Miyake, N. (2004). Explorations of scaffolding in complex classroom systems. The Journal of the Learning Sciences, 13(3), 265-272. https://doi.org/10.1207/s15327809j1s1303_1.

Durie, M. H. (1985). A Maori perspective of health. Social Science \& Medicine, 20(5), 483-486. https://doi. org/10.1016/0277-9536(85)90363-6.

Fawns, T. (2019). Postdigital education in design and practice. Postdigital Science and Education, 1(1):132145. https://doi.org/10.1007/s42438-018-0021-8.

Fawns, T., Aitken, G., \& Jones, D. (2019). Online learning as embodied, socially meaningful experience. Postdigital Science and Education, 1(2), 293-297. https://doi.org/10.1007/s42438-019-00048-9.

Forrest, R. H., Lander, P. J., Wawatai-Aldrich, N., \& Pearson, M. (2019). Patu ${ }^{\mathrm{TM}}$ Meke meter: Use in the classroom. New Zealand Journal of Educational Studies, 54, 327-344. https://doi.org/10.1007/s40841019-00145-0.

Goodyear, P., Banks, S., Hodgson, V., \& McConnell, D. (Eds.). (2004). Advances in research on networked learning. Dordrecht: Kluwer Academic Publishers.

Goodyear, P., \& Carvalho, L. (2014). Framing the analysis of learning network architectures. In L. Carvalho \& P. Goodyear (Eds.), The architecture of productive learning networks (pp. 48-70). New York: Routledge.

Goodyear, P., \& Dimitriadis, Y. (2013). In medias res: Reframing design for learning. Research in Learning Technology, 21, 1-13. https://doi.org/10.3402/rlt.v21i0.19909.

Gourlay, L., \& Oliver, M. (2018). Student engagement in the digital university: Sociomaterial assemblages. New York: Routledge.

Green, J. K., \& Huntington, A. D. (2017). Online professional development for digitally differentiated nurses: An action research perspective. Nurse Education in Practice, 22, 55-62. https://doi.org/10.1016/j. nepr.2016.11.009.

Hodges, C., Moore, S., Lockee, B., Trust, T., \& Bond, A. (2020). The difference between emergency remote teaching and online learning. EDUCAUSE Review. https://er.educause.edu/articles/2020/3/thedifference-between-emergency-remote-teaching-and-online-learning. Accessed 1 Aug 2020.

Hodgson, V., \& McConnell, D. (2019). Networked learning and postdigital education. Postdigital Science and Education., 1(1), 43-64. https://doi.org/10.1007/s42438-018-0029-0.

Hodgson, V., McConnell, D., \& Dirckinck-Holmfeld, L. (2012). The theory, practice and pedagogy of networked learning. In L. Dirckinck-Holmfeld, V. Hodgson, and D. McConnell (Eds.), Exploring the theory, pedagogy and practice of networked learning (pp. 291-305). New York: Springer. https://doi. org/10.1007/978-1-4614-0496-5_17. 
Hodgson, V., de Laat, M., McConnell, D., \& Ryberg, T. (Eds.). (2014). The design, experience and practice of networked learning. New York: Springer.

Jandrić, P. (2017). Learning in the age of digital reason. Rotterdam: Sense.

Jandrić, P. (2020). Postdigital research in the time of Covid-19. Postdigital Science and Education, 2(2), 233238. https://doi.org/10.1007/s42438-020-00113-8.

Jandrić, P., \& Boras, D. (2015). Critical learning in digital networks. Switzerland: Springer.

Jandrić, P., Knox, J., Besley, T., Ryberg, T., Suoranta, J., \& Hayes, S. (2018). Postdigital science and education. Educational Philosophy and Theory, 50(10), 893-899. https://doi.org/10.1080 /00131857.2018.1454000.

Jones, C. (2015). Networked learning: An educational paradigm for the age of digital networks. Switzerland: Springer International Publishing.

Jowsey, T., Foster, G., Cooper-Ioelu, P., \& Jacobs, S. (2020). Blended learning via distance in pre-registration nursing education: A scoping review. Nurse Education in Practice, 44, 102775. https://doi.org/10.1016/j. nepr.2020.102775.

Kenzig, M. J. (2015). Lost in translation: Adapting a face-to-face course into an online learning experience. Health Promotion Practice, 16(5), 625-628. https://doi.org/10.1177/152483991558829.

Kolodner, J., Camp, P., Crismond, D., Fasse, B., Gray, J., Holbrook, J., Puntambekar, S., \& Ryan, M. (2003). Problem-based learning meets case-based reasoning in the middle school science classroom: Putting learning by design into practice. The Journal of the Learning Sciences, 12(4), 495-548. https://doi. org/10.1207/S15327809JLS1204_2.

Meyer, J. P., \& Allen, N. J. (1991). A three-component conceptualization of organizational commitment. Human Resource Management Review, 1, 61-89.

Meyer, J. P., Stanley, D. J., Herscovitch, L., \& Topolnytsky, L. (2002). Affective, continuance, and normative commitment to the organization: A meta-analysis of antecedents, correlates, and consequences. Journal of Vocational Behavior, 61(1), 20-52. https://doi.org/10.1006/jvbe.2001.1842.

Munoz, J. A., Hernandez, D., Carvalho, L., Thompson, K., Wardak, D., Martinez-Maldonado, R., \& Goodyear, P. (2018). 4FAD: A framework for mapping the evolution of artefacts in the learning design process. Australasian Journal of Educational Technology, 34(2), 16-34. https://doi.org/10.14742 /ajet.3706.

Ryberg, T., \& Sinclair, C. (2016). The relationships between policy, boundaries and research in networked learning. In T. Ryberg, C. Sinclair, S. Bayne, \& M. de Laat (Eds.), Research, boundaries, and policy in networked learning (pp. 1-20). Cham: Springer. https://doi.org/10.1007/978-3-319-31130-2_1.

Swan, K., Garrison, D. R., \& Richardson, J. C. (2009). A constructivist approach to online learning: The Community of Inquiry framework. In C. R. Payne (Ed.), Information Technology and Constructivism in Higher Education: Progressive Learning Frameworks (pp. 43-57). IGI Global. https://doi.org/10.4018 1978-1-60566-654-9.

Williamson, B., Eynon, R., \& Potter, J. (2020). Pandemic politics, pedagogies and practices: Digital technologies and distance education during the coronavirus emergency. Learning, Media and Technology, 45(2), 107-114. https://doi.org/10.1080/17439884.2020.1761641

Wenger, E. (1998). Communities of practice: Learning, meaning, and identity. Cambridge: Cambridge University Press.

\section{Affiliations}

\section{Jennifer K. Green ${ }^{1}$ - Marla S. Burrow ${ }^{2}$ - Lucila Carvalho ${ }^{3}$}

1 School of Nursing, Massey University, Auckland, New Zealand

2 School of Nursing, Massey University, Palmerston North, New Zealand

3 Institute of Education, Massey University, Auckland, New Zealand 